\title{
Ameliorating effect of Alteplase in bleomycin-induced pulmonary fibrosis in adult rats
}

\author{
Mahdi M.Thuwaini ${ }^{1}$, Hanaa S.Kadhem ${ }^{2}$, Ali Esmail Al-Snafi ${ }^{3}$, Maha K.Abrahem ${ }^{4}$ \\ ${ }^{1}$ Department of laboratory Investigation, College of Medical and Healthy Techniques/ \\ Southern Technical University, \\ ${ }^{2}$ Department of pathological analysis, College of Science, Basra University, ${ }^{3}$ Department \\ of Pharmacology, College of Medicine, Thi qar University- Iraq \\ mahdi.murshd@stu.edu.iq
}

\begin{abstract}
The goal of this study was to see if alteplase may help adult rats suffering from bleomycin-induced lung fibrosis. Alteplase $0.9 \mathrm{mg} / \mathrm{kg}$ i.p. as a single dose daily for 3 weeks, significantly ameliorated the declined serum levels of SOD and GSHpx, and significantly, decrease the elevated level of hydroxyproline in (BLM) treated rats. The bulk of the alveolar walls were filled by collagenous fibres with diffuse cellular infiltration, bands of collagen fibres, and increased macrophages and fibroblast cells in sections of lung tissue from BLM-treated rats. The lung of rats treated by alteplase in combination with (BLM) revealed that fibrotic lesions appeared less, with mild inflammatory cells, minimum blood vessels congestion and most parenchyma tissue appeared similar to a normal structure. As a result, the findings could provide one treatment option for preventing lung fibrosis caused by anticancer therapy.
\end{abstract}

Keywords: Alteplase, Bleomycin, Pulmonary fibrosis, rats, GSH, SOD, HYP

\section{Introduction}

In a reparative process, fibrosis is the production of extra fibrous tissue in tissue [1]. Interstitial lung injury with tissue fibrosis and a loss of lung elasticity characterise pulmonary fibrosis (PF). PF can be caused by a variety of disorders or it might be idiopathic, meaning there is no recognised cause. There were three forms of lung tissue fibrosis as well: Replacement fibrosis, which happens in fibrosing alveolitis (IPF) and extensive allergy alveolitis [2], localised fibrosis in reaction to irritants, such as coal dust and silica, and diffuse parenchymal lung disease (DPLD), which occurs in fibrosing alveolitis (IPF) and extensive allergic alveolitis. There are a variety of methods for modelling (PF) and/or inducing lung tissue damage in animal models to obtain a realistic picture of human disease. Because there are pathologic similarities between fibrotic reactions in human and rodent lungs, animal models are an excellent tool for investigating pathologic changes in vivo. [3-4]. Various animal models of $(\mathrm{PF})$ have been developed, however, to examine potential therapeutics for 
the disease (PF). Chemical induction by bleomycin (BLM) is the most commonly used model in rodents (mouse, rats and hamster) [3]. Most of pulmonary fibrosis inducing models were stimulated lung-injury in response to oxidative stress.

Bleomycin, the anticancer drug, caused lung cell damage and fibrosis by inducing lipid peroxidation, independent from its effect on DNA. Therefore, one of the serious side effects of BLM in humans has been observed in the lungs, which may progress to fatal diffuse (PF) [5-8].

This research was designed to investigate the ameliorating effect of alteplase in bleomycininduced pulmonary fibrosis in adult rats

\section{Material and methods}

\subsection{Animals}

Albino Wister male rats (Rattus norvegicus) weighing 200-250 g were obtained from ThiQar University's College of Science's animal centre. All animals were provided free access to food and water, and were kept at a constant temperature of $22 \pm 3$ degrees Fahrenheit with a 12-hour light/dark cycle.

\subsection{Experimental design}

Animals were randomly assigned to one of four groups (10 rats each). The rats in group 1 (Control group) were given $0.5 \mathrm{ml} / \mathrm{animal} / \mathrm{daily}$ i.p. of sterile saline solution (the vehicle). For three weeks, Group 2 got bleomycin $15 \mathrm{mg} / \mathrm{kg} /$ i.p. three times weekly. Group 3 received alteplase $0.9 \mathrm{mg} / \mathrm{kg}$ i.p. as a single dose daily for 3 weeks (Benoitet al., 2010). Group 4 received bleomycin and alteplase simultaneously at doses, periods and administration similar to that mentioned in the groups 2 and 3. All the treatments were dissolved in normal saline and were administered for 3 weeks (9). The rats were anaesthetized with chloroform and venous blood samples were taken via direct heart puncture into sterilised tubes at the conclusion of the experiment. Sera was kept in a deep freezer.

\subsection{Estimation of GSHpx, SOD and HYP}

According to the kit instructions, serum glutathione peroxidase (GSHpx), superoxide dismutase (SOD), and hydroxyproline (HYP) were tested (Cusabio Eliza kit, catalo no.

CSB-E 121144r).

\subsection{Histopthological examination}

Lung tissue samples were taken from sagittal lung slices, fixed in $10 \%$ formalin for 24 hours, then washed, dehydrated, clarified, and embedded in paraffin; sections of around $4 \mathrm{~m}$ were stained with Hematoxylin-Eosin for microscopic analysis.

\subsection{Statistical analysis}

The paired students T-test was used to assess differences between groups. $\mathrm{P}<0.05$ was used to determine whether differences were statistically significant. 


\section{Results}

The serum level of SOD in the control was $9.42 \pm 1.08 \mathrm{Pg} / \mathrm{ml}$, administration of alteplase did not induce significant changes in the serum SOD $(9.270 \pm 0.591 \mathrm{Pg} / \mathrm{ml})$, however, SOD was significantly declined in bleomycin group $(7.77 \pm 0.644 \mathrm{Pg} / \mathrm{ml})(\mathrm{P}<0.01)$, while administration of alteplase with bleomycin significantly restored the serum SOD level to the normal. The level of seum GSHpx was also decreased significantly in bleomycin treated group $(17.04 \pm 1.52 \mathrm{MIU} / \mathrm{ml})$ compared with control $(33.18 \pm 3.444 \mathrm{MIU} / \mathrm{ml}) \quad(\mathrm{P}<0.001)$, while alteplase did not affected the level of GSHpx when administered alone $(30.62 \pm 3.92 \mathrm{MIU} / \mathrm{ml})$ but it restored the level of GSHpx to normal limit when administered with bleomycin $(30.07 \pm 2.00 \mathrm{MIU} / \mathrm{ml})$. On the other hand, the serum level of hydroxyproline was $1.44 \pm 0.20$ $\mu \mathrm{g} / \mathrm{ml}$ in the control group, it was did not change by alteplase $(1.67 \pm 0.19 \mathrm{MIU} / \mathrm{ml})$, but it was significantly increased by bleomycin $(2.86 \pm 0.12 \mathrm{MIU} / \mathrm{ml})(\mathrm{P}<0.0001)$, while alteplase significantly ameliorated the effect of bleomycin on hydroxyproline $(1.54 \pm 0.34 \mathrm{MIU} / \mathrm{ml})$ (Table 1).

Normal architecture, a spongy appearance of the lung with thin alveolar septa, clear alveolar cavities, and normal alveolar ducts were observed microscopically in the control group's rat lung sections. The alveoli were evenly dispersed and the lung tissue appeared normal. The alveolar epithelial tissue lining and loose connective tissue included a large capillary network around the alveoli, forming the interalveolar septa. The alveolar ducts have several alveoli openings along their length, and the alveolar sacs form at the end of the ducts (Figure 1). The histological evaluation of lung sections from rats given alteplase revealed normal histological characteristics, which were similar to the sections from the control group (Figure 2).

The bulk of the alveolar walls were filled by collagenous fibres with diffuse cellular infiltration, as well as bands of collagen fibres, with an increase in macrophages and fibroblast cells in BLM-treated rats' lung sections (figure 3). The sections of the lung of rats treated by alteplase in combination with (BLM), revealed that fibrotic lesions appeared less, with mild inflammatory cells, minimum blood vessels congestion and most parenchyma tissue appeared similar to normal structure (figure $4 \& 5$ ).

Table 1: Alteplase's effect on superoxide (SOD), glutathione peroxidase (GSHpx), and hydroxyproline (HYP) in blood serum of rats with bleomycin-induced pulmonary fibrosis.

\begin{tabular}{|l|l|l|l|}
\hline Groups & SOD Pg/ml & GSHpx MIU/ml & HYP $\mu \mathrm{g} / \mathbf{m l}$ \\
\hline Control & $9.42 \pm 1.08^{\mathrm{a}}$ & $33.18 \pm 3.44^{\mathrm{a}}$ & $1.44 \pm 0.20^{\mathrm{a}}$ \\
\hline Bleomycin & $7.77 \pm 0.644^{\mathrm{b}}$ & $17.04 \pm 1.52^{\mathrm{b}}$ & $2.86 \pm 0.12^{\mathrm{b}}$ \\
\hline Alteplase & $9.27 \pm 0.591^{\mathrm{a}}$ & $30.62 \pm 3.92^{\mathrm{a}}$ & $1.67 \pm 0.19^{\mathrm{a}}$ \\
\hline BLM+Alteplase & $9.08 \pm 1.09^{\mathrm{a}}$ & $30.07 \pm 2.00^{\mathrm{a}}$ & $1.54 \pm 0.34^{\mathrm{a}}$ \\
\hline
\end{tabular}


Vertically similar letter means not significant 


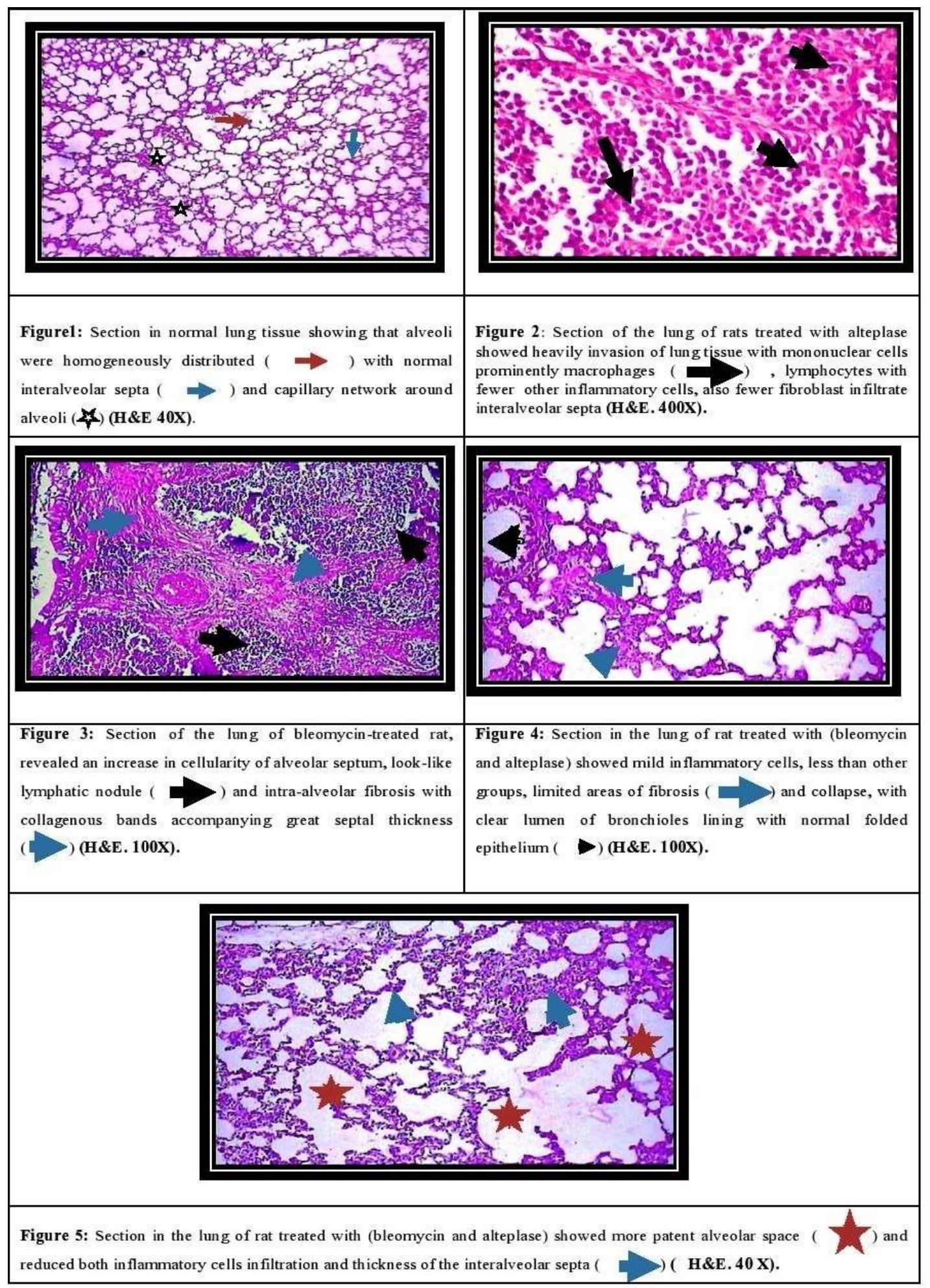




\section{Discussion}

Antineoplastic medicines frequently produce pulmonary fibrosis as a side effect. The goal of this investigation was to see if alteplase had any protective properties. To examine potential therapeutics for pulmonary fibrosis, various animal models of pulmonary fibrosis have been established (PF). The most frequent model for PF is bleomycin-induced lung fibrosis, which has a characteristic inflammatory pattern. In mice and rats (mouse, rat and hamster). Usuki and Fukua (10) observed that giving bleomycin to rodents causes histological changes that are nearly identical to those seen in human pulmonary fibrosis.

As in our results, the previous studies also showed that rat serum hydroxyproline was significantly increased, in bleomycin induced pulmonary fibrosis in rats (11-15). Furthermore, bleomycin induced significant deleterious changes in antioxidant status. The declined antioxidant status in our study was also recorded by many workers $(12,16)$. They discovered that a healthy balance of oxidants and antioxidants was one of the most critical factors in maintaining lung homeostasis, protecting the lungs from a variety of pathological diseases, and promoting normal healing.

The histopathological lesions that appeared with bleomycin in this study were similar to those recorded by many authors (17-18). The histopathological lesions induced by bleomycin confirmed that injurious effects of bleomycin. Bleomycin-treated animals showed prominent parenchymatous disruption manifested by the appearance of over-expanded alveoli with thinning, destruction of the interalveolar septa and connection of many alveoli together. These finding, were similar to the picture of the emphysematous lung previously described (19). These could be attributed to proteolytic parenchyma destruction. Furthermore, it was reported that damage of the interstitial tissue could be followed by alveolar and interstitial edema, inflammation and breakdown of connective tissue (20-21), all these findings matched with our histological results. In the current study, the treatment with alteplase has been proven beneficial as it attenuated lung pathology induced by bleomycin. Where it reduced pulmonary inflammation, reduced extensive areas of collagen deposition whether interalveolar, around alveoli or peribronchioleoli, around blood vessels and subpleura zone. It also decreased inflammatory cells infiltration, re-epithelization of cellular lining alveoli. The effect of alteplase could be attributed to its fibrin dissolving characteristics and its antioxidant effects in BLM-induced pulmonary damage, where ROS led to the depletion of glutathione and oxidant/antioxidant imbalance, subsequently. Alteplase blocked this process and eventually improved the case of the lung.

\section{Conclusion}

According to our results, alteplase decreased hydoxyproline which elevated in pulmonary fibrosis induced by bleomycin. It also increase the antioxidant status which declined by bleomycin. Furthermore it ameliorated the histological alterations in the lung. Accordingly, the results confirmed the protective effects of fibrinolytic drugs in pulmonary fibrosis.

\section{References}


1. Wynn TA. Common of unique mechanizes regulate fibrosis in various fibro proliferative diseases. J Clin Merest. 2007;117 (3): 524-529.

2. Belloli EA, Beckford R, Hadley R and Flaherty KR. Idiopathic non-specific interstitial pneumonia. Respirology. 2016; 21(2):259-68.

3. Moeller A, Ask K and Warburton D. Gauldie, J. and Kolb, M. The bleomycin animal model: a useful tool to investigate treatment options for idiopathic pulmonary fibrosis. Int J Bio Chem Cell Biol 2008; 40(3): 362-382.

4. Antje M, Juan C, Rodriguez Z, Linggiaow L, Jack G and Martin K. Models of pulmonary fibrosis. Respir. Diseases. 2006; 3(3): 243-249.

5. Epstein E. Intralesional bleomcin and Raynaud's phenomenon. J Am Acad Dermatol 1991; 24 (9):3-6.

6. Epstein JB, Gorsk M, Wong FL and Millnery A. Topical bleomcin for the treatment of dysplastic oral leukoplakia. Cancer. 1998; 83: 629-634.

7. Fasske $\mathrm{E}$ and Morgenroth K. Experimented bleomycni lung in mice a contribution to the pathogenesis of pulmonary fibrosis. New York, 1983: 133-146.

8. Gartner LP and Hiatt JL. Color textbook of histology: Respiratory system. $3^{\text {rd }}$ ed. Sanders an Imprint of Elsevier Inc, 2007; 15: 345-365.

9. Mahdi M. Thuwaini, Ali E. Al-Snafi, Hanaa S. Khadem. Ameliorating effect of urokinase in bleomycin- induced pulmonary fibrosis in rats. International Journal of Pharmaceutical Research. 2021; 13(2): 2980-2983.

10. Usuki J and Fukuda Y. Evolution of three patterns of intra-alveolar fibrosis produced by bleomycin in rats Pathol Int. 1995; 45(8):552-564.

11. Avissar N, Finkelstein JN, Horowitz S, Willey JC, Coy E, Frampton MW, Watkins RH, Khullar P, Xu YL and Cohen HJ. Extracellular glutathione peroxidase in human lung epithelial lining fluid and in lung cells. Am J Physiol. 1996; 270:L173-L182.

12. Fattmann CL, Chu CT and Oury TD. Experimental models of asbestos-related diseases. In: Roggliv, Oury TD, Sporn, TA. (Ed.). Pathology of asbestos associated diseases. $2^{\text {nd }}$ ed. New York: Springer- Verlag, 2005; 256-308.

13. Yao HW, Zhu JP, Zhao MH and Lu Y. Losartan attenuates bleomycin-induced pulmonary fibrosis in rats. Respiration. 2006; 73:236-242.

14. Molina-Molina M, Serrano-Mollar A, Bulbena O, Fernaftdez-Zabalegui L, Closa D, Marin-Arguedas A, Torrego A, Mullol J, Picado C and Xaubet A. Losartan attenuates bleomycin induced lung fibrosis by increasing prostaglandin E2 synthesis. J Thorax. 2006; 61: 604-610.

15. Giri SN, Chen ZL, Younker WR and Schiedt MJ. Effects of intratracheal administration of bleomycin on GSH-shuttle enzymes, catalase, lipid peroxidation, and collagen content in the lungs of hamsters. Toxicol Appl Pharmacol. 1983; 71(1):132-141.

16. Rahman I and MacNee W. Oxidative stress and regulation of glutathione in lung inflammation. Eur Respir J. 2000; 16(3):534-554.

17. Cooper J, Zitnik R and Mathay R. Mechanisms of drug induced pulmonary disease. Annu Rev Med. 1988; 39: 395- 494.

18. Izbicki G, Segel MG, Christensen TG, Conner MW and Brener R. Time course of bleomycin-induced lung fibrosis. Int J Exp Path. 2002; 83(3):111-119. 
19. Borzone G, Moreno R, Urrea R, Menese M, Oyarzun M and Lisboa C. Bleomycin-induced chronic lung damage does not resemble idiopathic pulmonary fibrosis. Am J Respir Crit Care Med. 2001;163:1648-53.

20. Sullivan JB, Krieger GR. Clinical environmental health and toxic exposures. $2^{\text {nd }}$ ed. Philadelphia: Lippincott Williams \& Wilkins, 2001.

21. Jafarian D, Rabbani TG, MirMohammed Sadeghi H, Moghaddam N, Alvavis A, Mahmodi F and Safacian L. Development and time- course of bleomycin-induced pulmonary fibrosis in mice. DARU. 2007; 15(1): 1-6. 